\title{
Horizontal drilling drainage as a preventive measure for water induced landslide risk reduction: A case study from Sindhuli Road, Section I, Nepal
}

\author{
*Shanmukhesh Chandra Amatya1 and Mikihiro Mori² \\ ${ }^{1}$ Nepal Landslide Society, Nepal \\ 2Nippon Koei Co. Ltd. Japan \\ *Corresponding author: amatyasc@gmail.com
}

\begin{abstract}
Nepal is a mountainous country which covers about $83 \%$ area of the Higher Himalaya, mountain and hills with rugged topography and highly tectonic geology. Most of those areas are prone to sediment related water induced disasters such as slope failure, debris flow, and landslide which are triggered due to torrential rainfall during the monsoon rainy season, and that causes the loss of lives and properties, infrastructures and environmental degradation each year. The annual rainfall ranges from 2000 to $3000 \mathrm{~mm}$ (in the Central Region of Nepal). The natural disasters cannot be prevented completely but efforts can be made for mitigating the impact of the disasters. Among the mitigation measures of water induced landslide disasters, the Horizontal Drilling Drainage Technology is one of the most effective counter measures of landslide risk reduction. The main purpose of this technology is to release the pore water pressure in the landslide mass by reducing the groundwater level. The landslide disaster prone Kamala Mai village area lies along the Sindhuli road section I, the National Highway, in Sindhuli District, Nepal which was generating subsidence and creeping of the road each year since many years back. This method was applied in the Sindhuli road Section I, Chanaige 29+300, Kamala Mai Village area. The result obtained from the application of the method shows an effective achievement to the Sindhuli road stability and the road users as well. Recommendation has been made to replicate the technology in other places of the country also in similar environment.
\end{abstract}

Keywords: Horizontal Drilling Drainage, Sediment Related Disaster, Sindhuli Road

Paper Received: 29 Jan 2018

Paper Accepted: 8 March 2018

\section{INTRODUCTION}

Nepal is a mountainous country which covers about $15 \%$ area of snow capped mountains of the Himalayan Region (altitude $4877-8848 \mathrm{~m}$ ) and $68 \%$ of hills and mountains including inner valleys, the Hilly Region (altitude 610-4877 m). Most of those areas are prone to sediment related water induced disasters such as slope failure, debris flow, and landslide which are triggered due to torrential rainfall during the monsoon rainy season. The average annual rainfall in the central region of the country ranges from $2000 \mathrm{~mm}$ to $3000 \mathrm{~mm}$. The geology here is young and fragile and steep morphology. So, most of the areas in mountains and hills are prone to those three types of sediment related water induced disasters such as slope failure, debris flow, and landslide (DPTC, 1999) and that causes the loss of lives and properties, infrastructures and environmental degradation each year.

The water induced disasters like landslide and flood only covers nearly about $50 \%$ of the total disaster events of Nepal. The different disasters occurred in the year 2073 BS (2016/17 AD) as per the data of Ministry of Home Affairs shows 526 casualties in Nepal (Fig. 1).

The natural disasters cannot be prevented completely but efforts can be made for mitigating the impact of disaster. In this regard the mitigation methods of those sediment related disasters as slope failure, debris flow and landslide are different from each other. Out of which the horizontal drilling drainage is one of the most effective mitigation methods for slow moving landslide. This technology was applied in the Sindhuli Road Section I, change 29+300, Kamalamai Municipality, Sindhuli District under the JICA pilot project of The Project for the Operation and Maintenance of the Sindhuli Road. The location of the study area is presented in the Fig. 2.

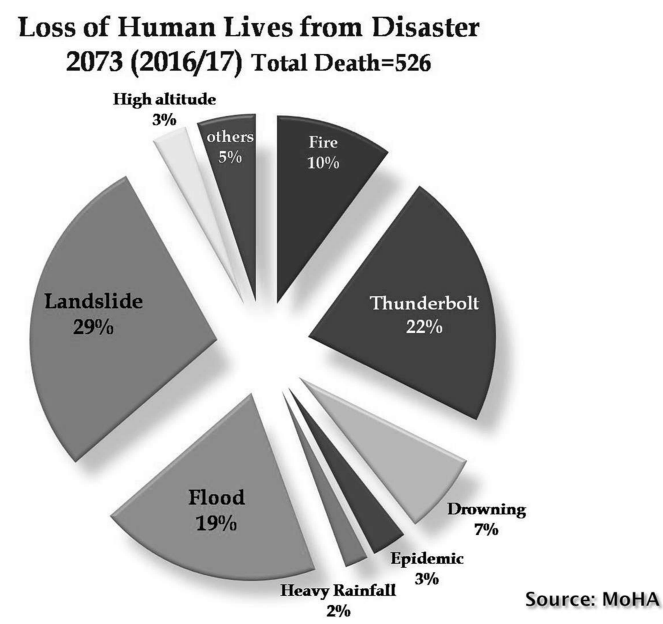

Fig. 1: Casualties from different disasters in Nepal (Source: MoHA) 


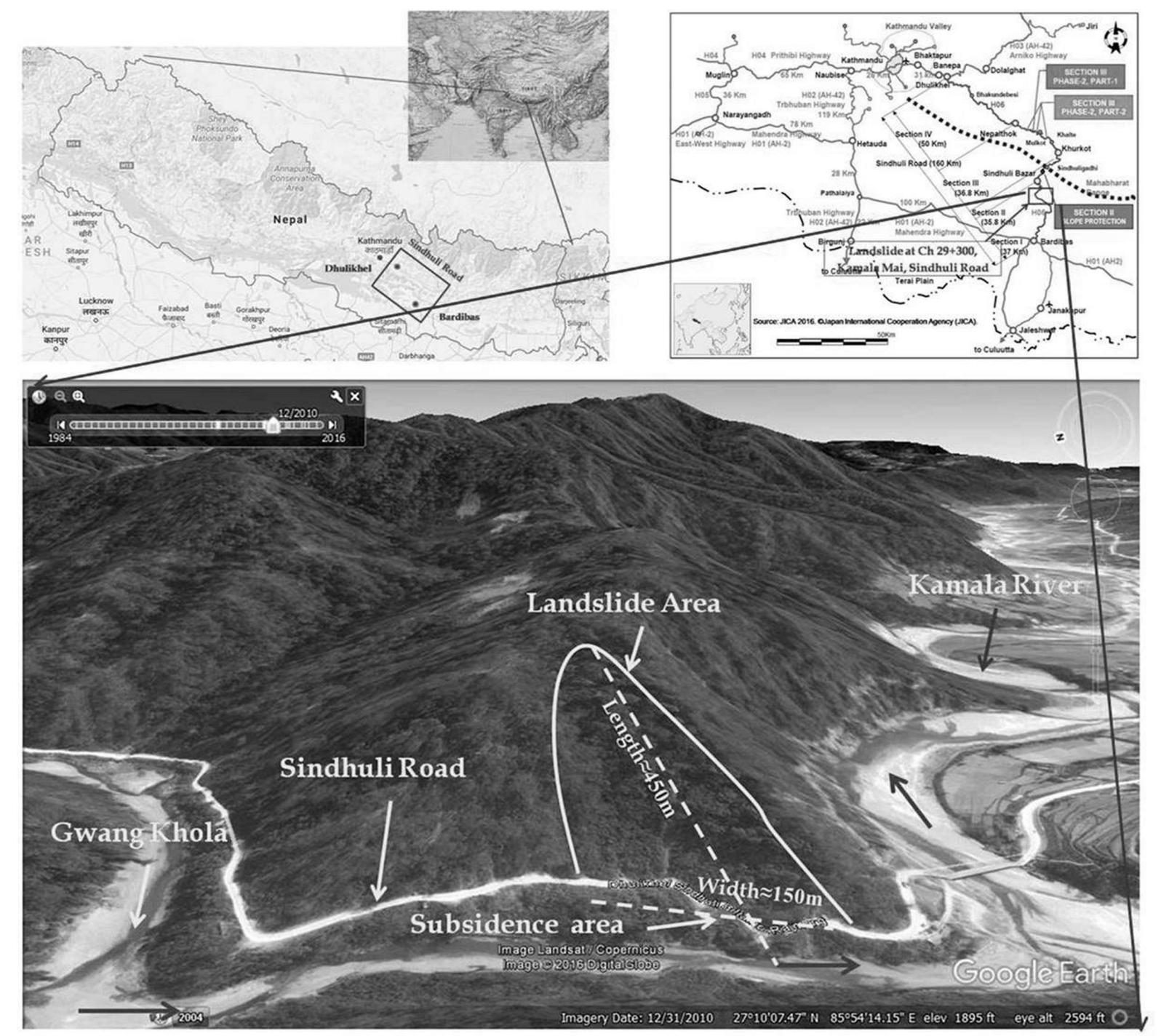

Fig. 2: Location map of study area

The Sindhuli Road (Dhulikhel-Sindhuli-Bardibas) is one of the most important principal roads in Nepal, linking the Kathmandu City with the Terai Plain area to the South-East area, constructed under grant-aid from the Government of Japan. The Sindhuli Road, having $160 \mathrm{~km}$ length in total, has been divided into four sections as,

- Section I: Bardibas-Sindhuli (37 km),

- Section II: Sindhuli-Khurkot (36 km),

- Section III: Khurkot-Nepalthok (37 km), and

- Section IV: Nepalthok-Dhulikhel (50 km)

The Section I was started in 1996 mainly for bridge construction works. The Section II and IV were started afterward and all three sections (sections I, II, and IV) had been completed by 2009. The construction of Section III was started from 2009 and completed on February 2015. As the result, the whole section of the Sindhuli Road was opened to the public and handed over to Department of Road (DOR) at the beginning of March, 2015, (JICA, 2015).

The major issue at 29+300, Kamalamai village area, Section I of the Sindhuli Road (National Highway), Sindhuli District, was generating subsidence and creeping of land mass each year since many years back. The landslide was activated due to pore water pressure and toe cutting by the Gwang Khola stream. The sliding land mass was crossing around $150 \mathrm{~m}$ length along the road and was disturbing the highway in each rainy season (Fig. 3). This study has made an effort to address the issue.

\section{TOPOGRAPHY}

The overview of the topography and land coverage of the landslide area covers from the elevation $475 \mathrm{~m}$ (MSL) at Gwang Khola stream to about 610 m (MSL) near the crown area of the landslide. The landslide area lies in the Siwalik 


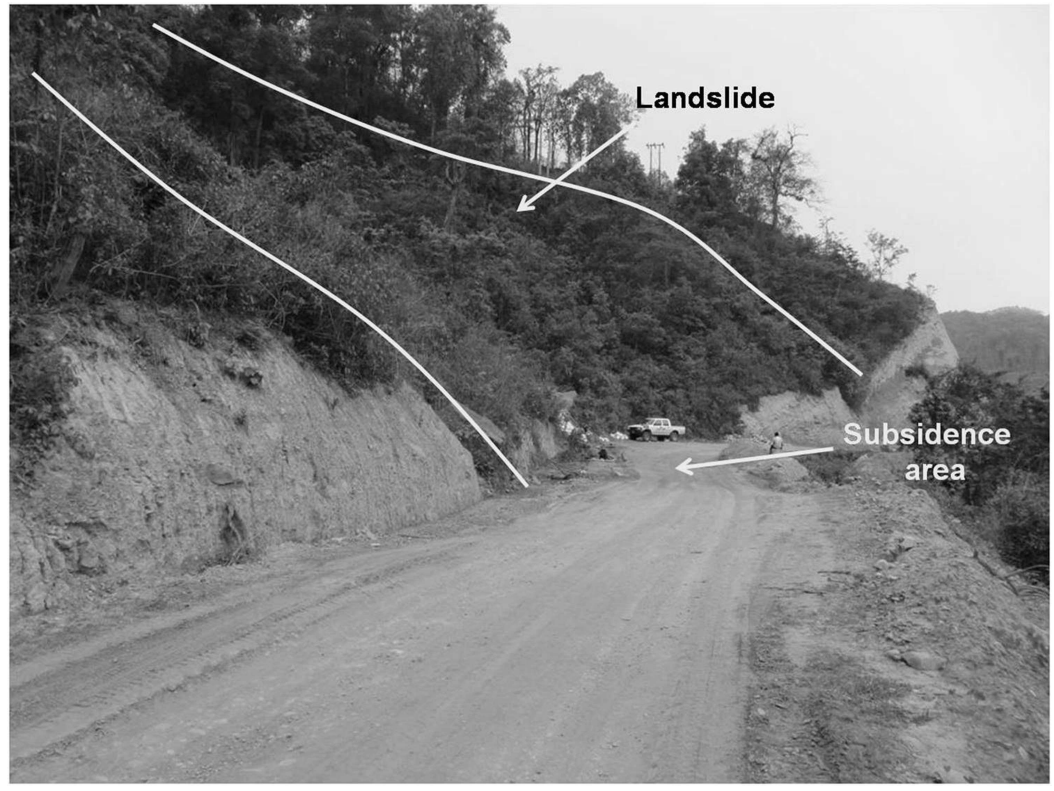

Fig. 3: Problem of the landslide area

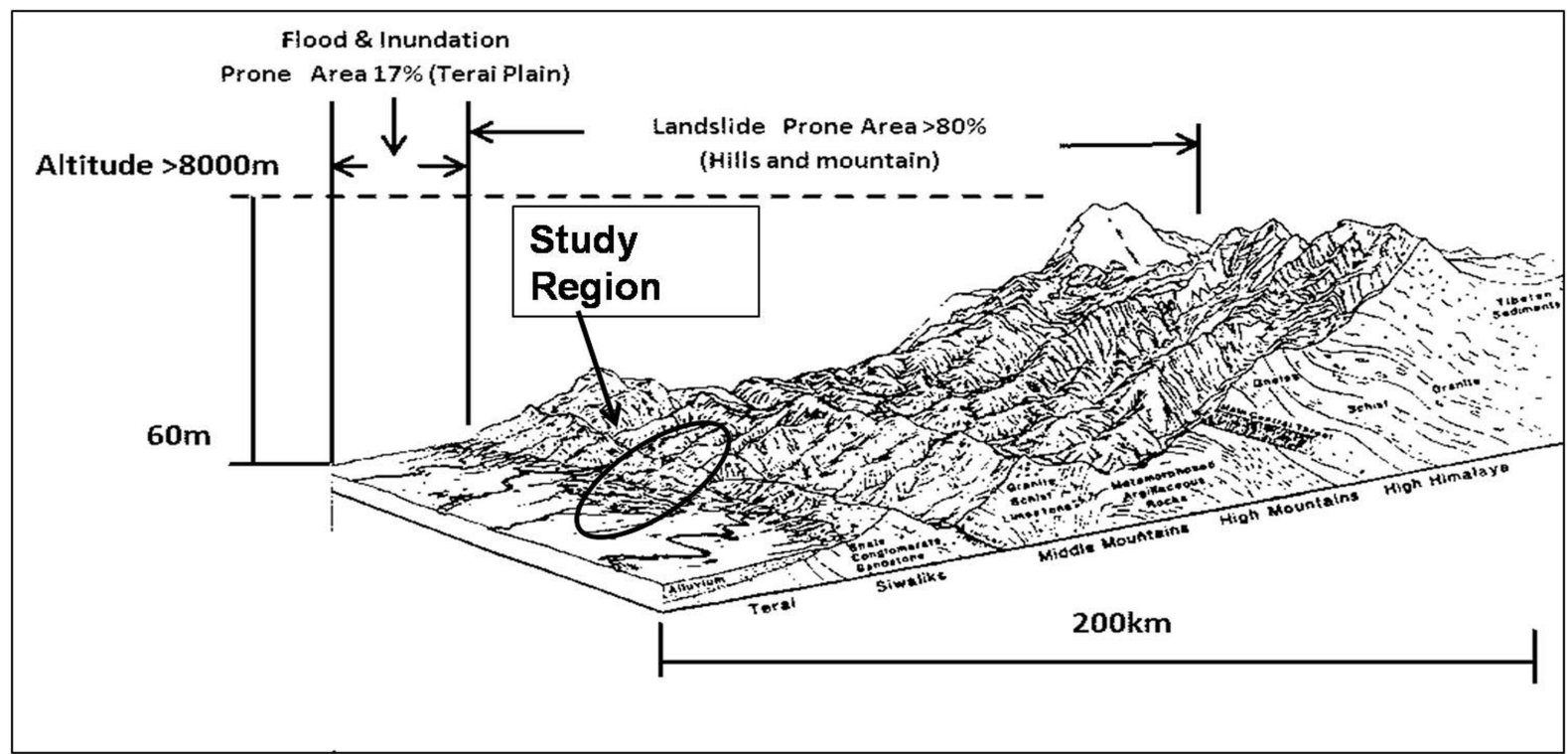

Fig. 4: Topography of the study area (Amatya and Joshi, 2015)

Range of Nepal. The study region is shown in the Fig. 4.

\section{HYDROLOGY}

The average annual rainfall distribution of Nepal shows the high rainfall distribution from 2000-4000 $\mathrm{mm}$ at middle and eastern part of the country. The study area belongs to the medium rainfall area from 500-2000 mm range (Fig. 5). The average annual rainfall of the study area is about $1951 \mathrm{~mm}$ (based on the rainfall data from 2008-2016, Sindhuli Bazar). The average monthly rainfall pattern of Sindhuli is presented in Fig. 6.

\section{GEOLOGY}

The landslide area under the present study falls in the Geological Map of Petroleum Exploration Block-8, Janakpur, Central Nepal published by Department of Mines and Geology (DMG, 2004). Geologically, the study area lies on the Upper Middle Siwalik (MS2), (DMG, 2004) Fig.7. The MS2 formation consists of mainly medium- to coarse-grained sandstone, pebbly sandstone with siltstone, mudstone and relicts of sandstone. The mudstone erodes quickly due the rainwater in each rainy season. Thus, the sandstone bed will be hanging out and toppled down which creates landslide. This environment is common in the Siwalik Range. 


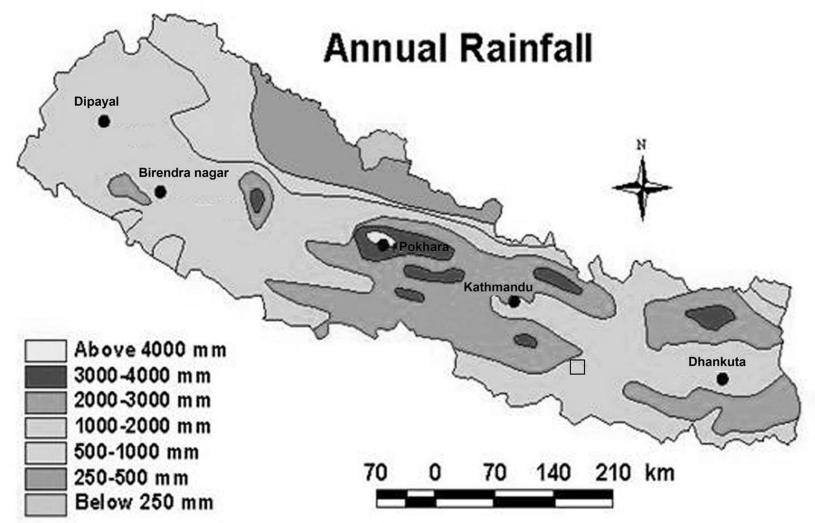

Fig. 5: Annual rainfall (source: DHM)

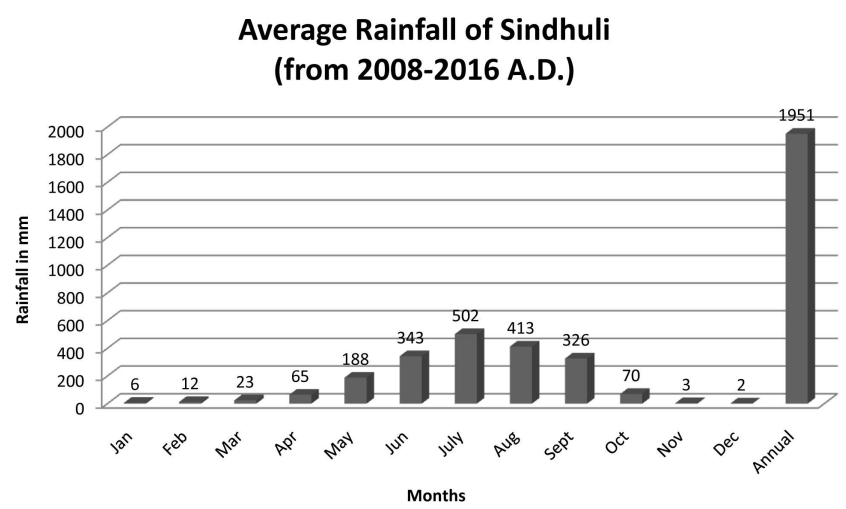

Fig. 6: Average monthly rainfall (source: DHM)

\section{MATERIALS AND METHODS}

The landslide of the Sindhuli Road, section I, 29+300, is generating subsidence and creeping of land mass each year since more than ten years. That became a major problem to the Sindhuli Road users and department of road.

The problem is related to the geology of the area, such as the landslide area lies on the mudstone and sandstone of the Siwalik range (DMG, 2004), where the mudstone softened and eroded quickly due the rainwater and the sandstone bed would be hanged out and toppled down. Those mass were slipped down with creeping toward the Sindhuli Road creating slip surface due to increase of pore water pressure during the rainy season. And more over the toe part of the landslide has been eroding by the Gwang Khola stream which accelerated the movement of the mass additionally. This process was continuing since many years back.

In this regard, the survey and investigation works were done by the expert study team whose members were from the Department of Road, Department of Water Induced Disaster Management (DWIDM), Sindhuli Road Maintenance Unit (SRMU) together with the JICA Experts, to address the landslide of the Sindhuli Road Section I, 29+300 problem. The study team planned six drilling sites in the landslide area for investigation of the landslide (PWRI, 2007), such as three

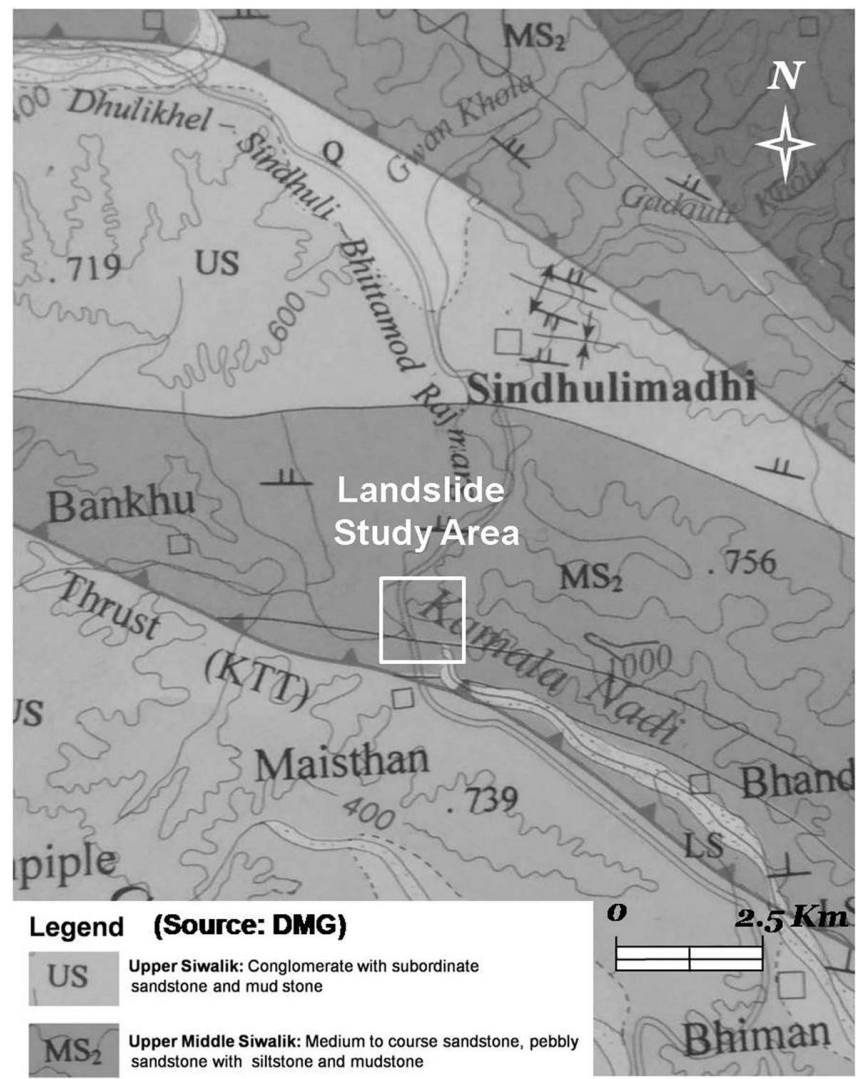

Fig. 7: Geology of the area (source DMG)

drilling holes in the central line of the landslide, two drilling holes in the left side of the landslide and one drilling hole in the right side of the landslide (Fig. 8).

The geological conditions of the landslide site were reported after the completion of the core drilling as presented in the lithological log Table 1. The lithological log in the Table 1 shows the tentative slip surface of the landslide mass around 9.5 to $10.5 \mathrm{~m}$ below ground level (BGL) and the soil type were wet, muddy, like slurry with wet sand.

The water level recorded in the bore holes of central line of the landslide exhibits $7.8 \mathrm{~m}$ (BGL) in the head part, $2.5 \mathrm{~m}$ (BGL) at the body part and $12.1 \mathrm{~m}$ (BGL) at the toe part of the landslide which exhibits the existence of more pore water pressure at body part.

A Strain gauge is one of the most important sensors of the electrical measurement technique whose resistance varies with applied force; it converts force, pressure, tension, weight, etc., into a change in electrical resistance which can then be measured. When external forces are applied to a stationary object, stress and strain are the result. Stress is defined as the object's internal resisting forces, and strain is defined as the displacement and deformation that occur.

Thus, the strain gauge technology provides a precise 


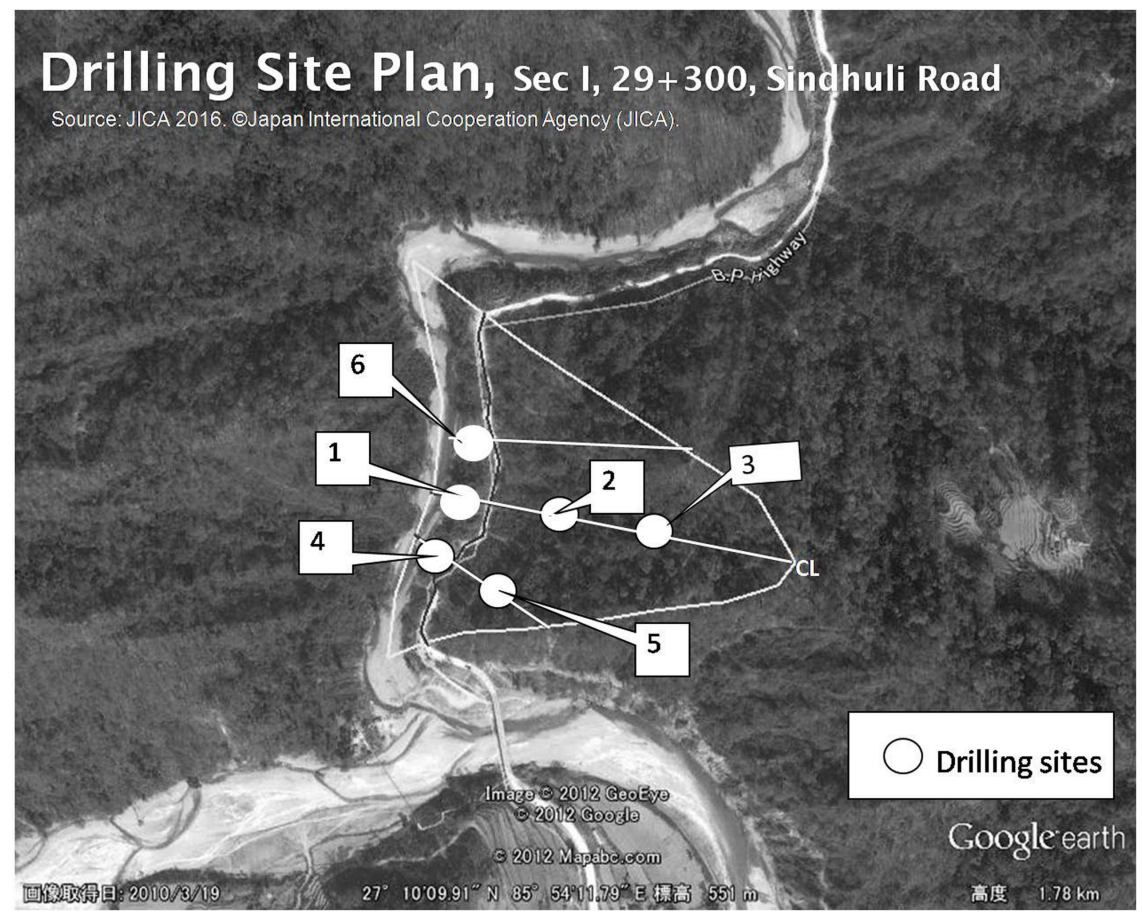

Fig. 8: Drilling site plan of the landslide (source: JICA, 2016)

data about the landslide. In this regard, the well known strain gauge technology was installed in all the six bore holes to have the precise slip surface of the landslide. The strain gauge was monitored each week from May to September 2012 that was from pre to post monsoon period. The strain gauge monitoring data analysis exhibited the slip surface of the landslide found at $10 \mathrm{~m}$ depth of the landslide which supports to the lithological $\log$ as well. The geological cross-section of the landslide at the central line (CL) is presented in the Fig. 9.

\section{Stability Analysis}

The stability analysis of the landslide was made using the Swedish slice method (also called as ordinary slice method). The formula of the Swedish slice method for the slope analysis is given by (PWRI, 2007);

$$
F S=\frac{\left(\sum \mathrm{N}-\sum \mathrm{U}\right) \times \tan \emptyset+\mathrm{c} \times \sum \mathrm{L}}{\sum \mathrm{T}}
$$

Where, $\mathrm{N}(\mathrm{KN} / \mathrm{m})=$ Normal force attributable to gravity of slice, $\mathrm{N}=\mathrm{W} \times \cos \alpha ; \mathrm{T}(\mathrm{KN} / \mathrm{m})=$ Tangential force attributable to gravity of the slice; $\mathrm{T}=\mathrm{W} \sin \alpha ; \alpha\left(^{\circ}\right)=$ Angle of the base of the slice to the horizontal; $\mathrm{U}(\mathrm{KN} / \mathrm{m})=$ Pore pressure acting on the base of the slice; $\mathrm{L}(\mathrm{m})=$ Length of sliding surface acting on the slice; $\mathrm{c}\left(\mathrm{kN} / \mathrm{m}^{2}\right)$ : = Cohesion of sliding surface; $\phi\left(^{\circ}\right)=$ Internal friction angle of sliding surface.

The factor of safety (Fs) for the stability analysis using the Swedish slice method was calculated with adopting the

Table 1: Lithological log of the landslide (source: JICA, 2014)

\begin{tabular}{|c|c|c|c|}
\hline Depth in $\mathbf{m}$ & Log & Lithology details & Remarks \\
\hline $0-9.5$ & & $\begin{array}{l}\text { Loose, highly weathered, fractured, fine-grained sandstone } \\
\text { aggregates mixed with mud stones in the upper layer }\end{array}$ & $\begin{array}{l}\text { depth varies upto } 9.0-11.0 \\
\mathrm{~m} \text { below ground level (BGL) }\end{array}$ \\
\hline $9.5-10.5$ & & $\begin{array}{l}\text { Weathered, wet mudstone like slurry followed by weathered, } \\
\text { wet sandstone }\end{array}$ & $\begin{array}{l}\text { depth varies from } 9.5-10.5 \mathrm{~m} \\
\text { (BGL) }\end{array}$ \\
\hline $10.5-11.5$ & & $\begin{array}{l}\text { Fresh brown-grey fine to medium-grained calcareous } \\
\text { indurated sandstone }\end{array}$ & $10.5-11.5 \mathrm{~m}(\mathrm{BGL})$ \\
\hline $11.5-15.0$ & & $\begin{array}{l}\text { Weathered calcareous fine-grained brown-grey } \\
\text { interbedding of sandstone and mudstone. }\end{array}$ & $11.5-15.0 \mathrm{~m}(\mathrm{BGL})$ \\
\hline $15.0-20.0$ & & $\begin{array}{l}\text { Fresh brown-grey fine to medium-grained calcareous } \\
\text { indurated sandstone }\end{array}$ & $11.5-20.0 \mathrm{~m}(\mathrm{BGL})$ \\
\hline
\end{tabular}




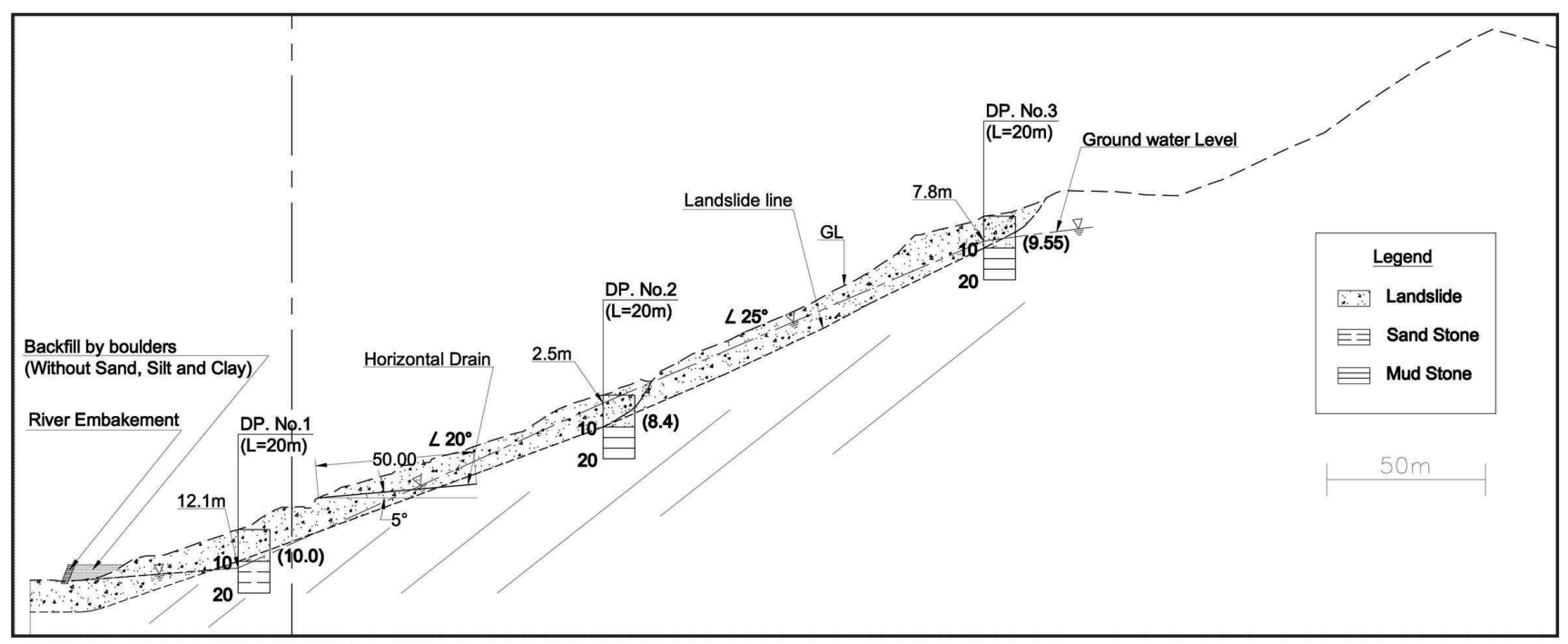

Fig. 9: Geological cross section at central line of the landslide (source: JICA, 2016)

values of cohesion $\mathrm{c}$ and the internal friction angle $\phi$ as shown in the Table 2. The scarps, bulges, settlement and cracked drainage show that the landslide movement is ongoing in rainy season and moving intermittently. In this regards, the initial factor of safety is considered less than 1 that is, 0.98 . Based on the discussion with experts of the Project for the operation and maintenance of the Sindhuli Road, JICA Expert Team Sindhuli Road Maintenance Unit (SRMU), Department of Road (DOR) and Department of Water Induced Disaster Management (DWIDM), the designed safety factor was decided to be 1.10 for road.

The major cause of the landslide movement in the study area is due to the increase of pore water pressure which increases the weight of the landslide and moves down. In this regard, the factor of safety was back calculated with changing the values of water level decreased to $1.5 \mathrm{~m}, 3 \mathrm{~m}$ and so on in the landslide area. As a result, in the initial Fs, the calculated Factor of safety was 1.0 and pore water pressure $\Sigma \mathrm{U}$ was found $12744 \mathrm{KN} / \mathrm{m}$ (Fig. 10). If the water level is considered to be decreased by $1.5 \mathrm{~m}$ drawdown, the Factor of safety changed to 1.128 and the pore water pressure $\Sigma \mathrm{U}$ decreased to $10331 \mathrm{KN} / \mathrm{m}$ (Fig. 11).
In the same way if the $\mathrm{v} \sum$ ter level is considered to be decreased by $3.0 \mathrm{~m}$ drawdown, the Factor of safety changed to 1.25 and the pore water pressure $\mathrm{U}$ decreased to $7966 \mathrm{KN} / \mathrm{m}$ (Fig. 12). Thus if the water level decreases by $1.5 \mathrm{~m}$ drawdown the designed factor of safety will be satisfied but if the water level decreases by $3.0 \mathrm{~m}$, it will be much more in safe side.

\section{RESULTS}

\section{Planning and design}

Considering the factor of safety calculation and stability analysis, the planning and design of the preventive measures were prepared.

It is clear from the materials and methods above that the major cause of the landslide is due to increase of pore water pressure in the body part of the landslide. The horizontal drilling drainage (sub-surface) will be one of the most appropriate technologies to reduce the pore water pressure in the landslide area. According to the practice in Japan, the sub-surface drainage distributed all over the landslide area can anticipate maximum

Table 2: Adopted values for factor of safety calculation (source: JICA, 2014)

\begin{tabular}{ccl}
\hline Item & Adopted value & \multicolumn{1}{c}{ Remark } \\
\hline Cohesion c & $10 \mathrm{kN} / \mathrm{m}^{2}$ & The thickness of landslide is approximately $10 \mathrm{~m}$. \\
Internal Friction Angle $\phi$ & $27.08^{\circ}$ & $\phi$ was calculated based on the assumed cohesion and initial safety factor. \\
Initial Safety Factor & $\mathrm{Fs}=0.98$ & $\begin{array}{l}\text { Scarps, bulges, settlement and cracked drainage show that landslide movement is } \\
\text { ongoing in rainy season and moving intermittently. }\end{array}$ \\
Designed Safety Factor & PFs $=1.10$ & $\begin{array}{l}\text { Based on discussion with the experts of Sindhuli Road Project, DWIDM and DoR, the } \\
\text { design safety factor was decided on the base of the environment of Landslide which is } \\
\text { wide and has possibility to move largely. Landslide liable to cause significant damage to } \\
\text { the road but there are no houses and cultivated land. }\end{array}$ \\
\hline
\end{tabular}




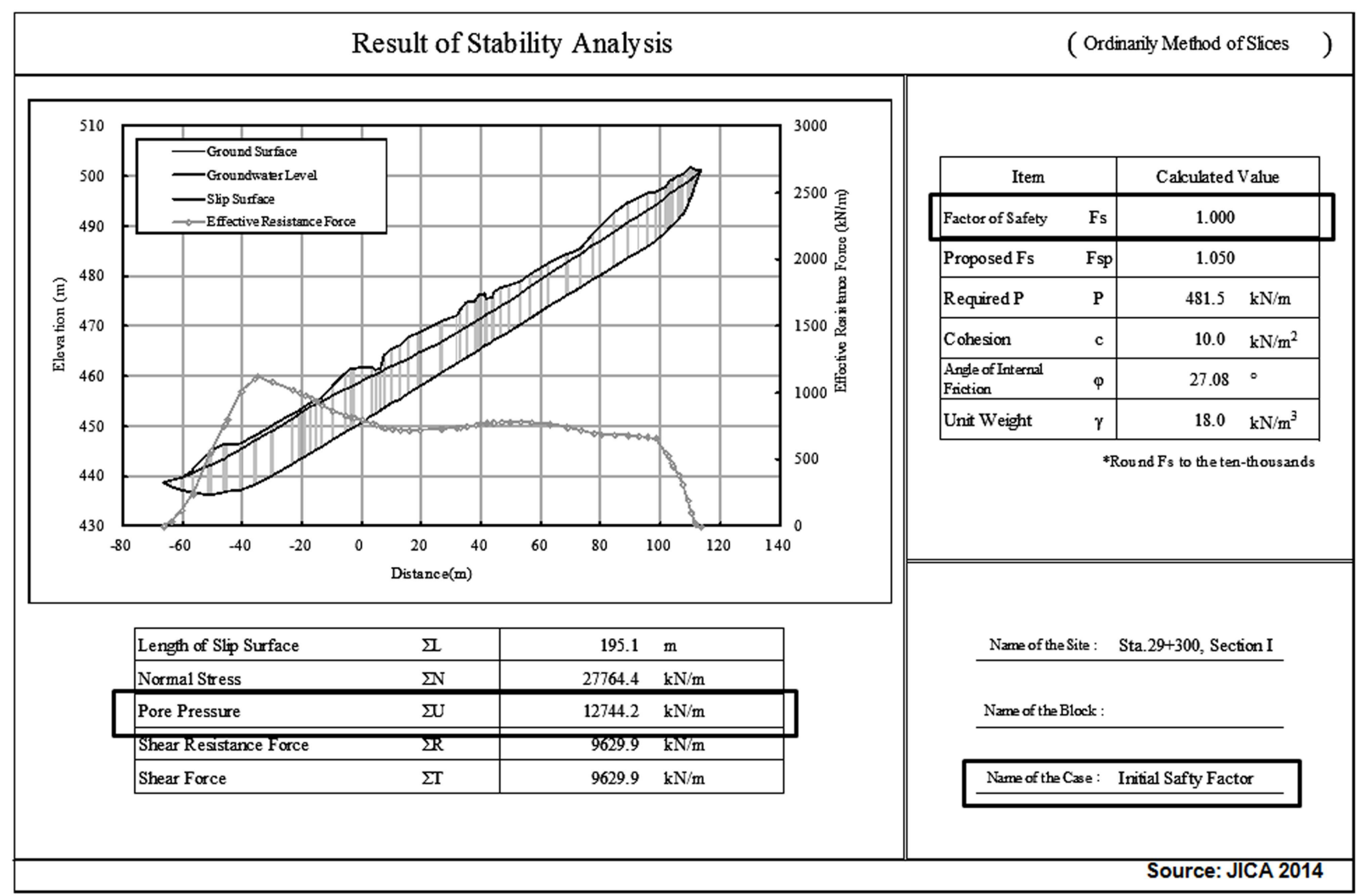

Fig. 10: Initial factor of safety (source: JICA, 2014)

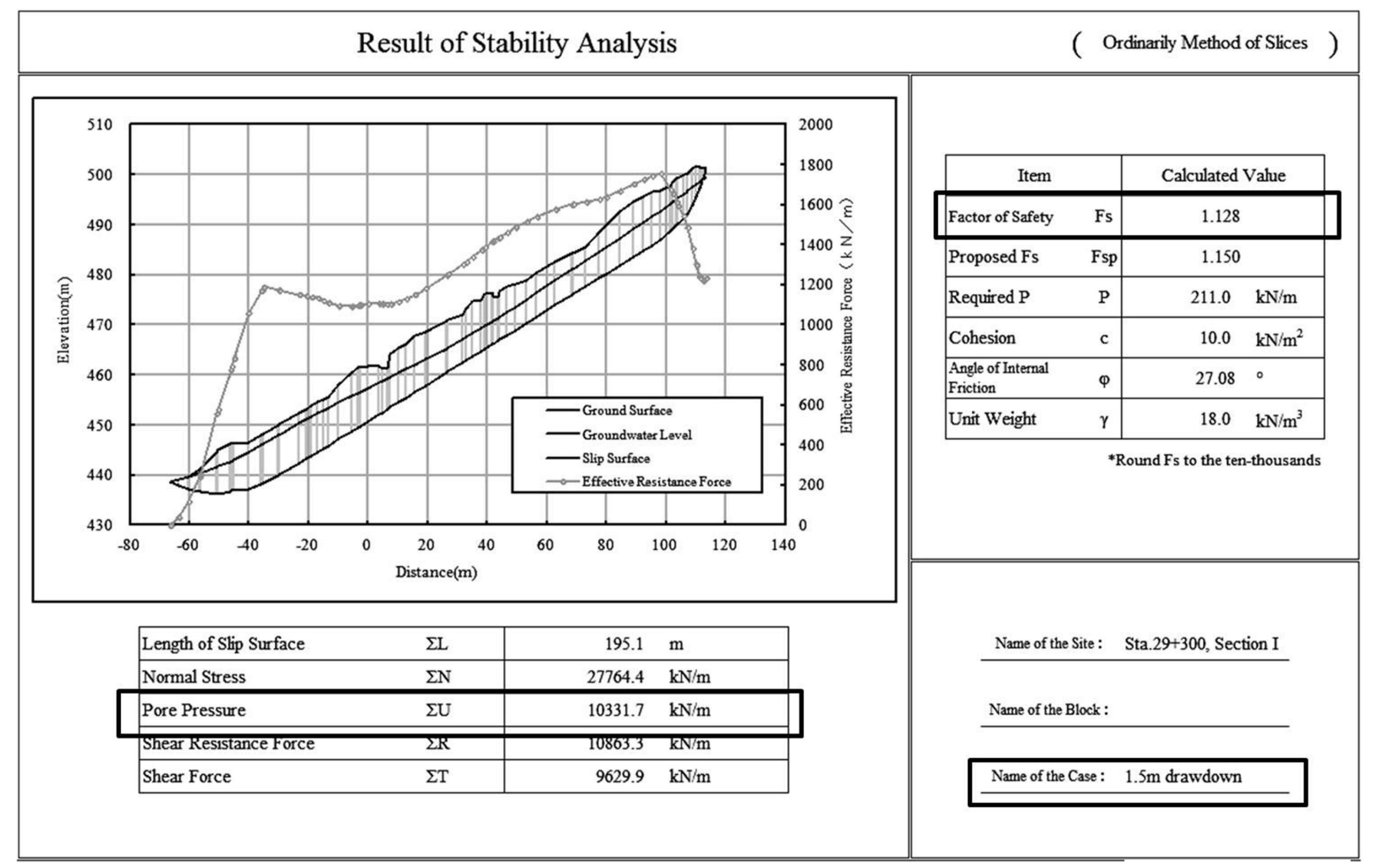

Fig. 11: Factor of safety in water level 1.5m drawdown (source: JICA, 2014) 


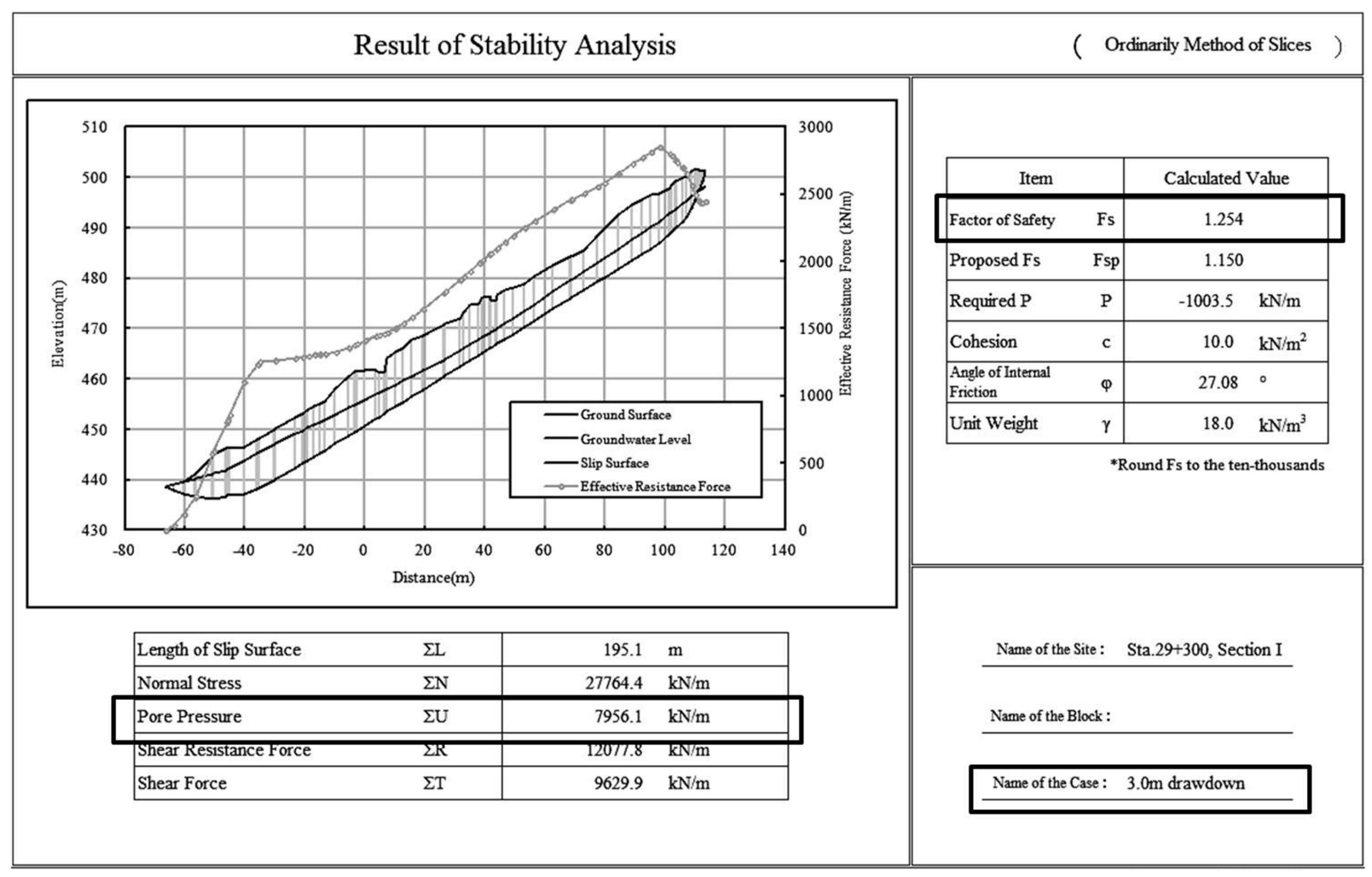

Fig. 12: Factor of safety in water level 3.0m drawdown (source: JICA, 2014)

$3.0 \mathrm{~m}$ drawdown of groundwater level. The safety factor in case of $3.0 \mathrm{~m}$ as well as $1.5 \mathrm{~m}$ drawdown for the landslide can satisfy the designed safety factor. So, the Horizontal drilling (subsurface) drainage was adopted for the countermeasure of the landslide.

The Horizontal drilling (sub-surface) drainages were planned in such a way that, they would cover most part of the landslide area to draw down the water level. Five clusters of total 51 horizontal drilling drainages (total length $2254 \mathrm{~m}$ ) were planned and the lengths of the horizontal drilling drainages were designed in such a way that they will cross the slip surface of the landslide and the inclination of the drainage pipes were set at $5^{0}$. Two clusters of horizontal drilling drainages each consists of 8 horizontal drilling drainages with $48 \mathrm{~m}$ length each were planned to install at the head part of the landslide. One cluster of 13 horizontal drilling drainages with $50 \mathrm{~m}$ length each were planned to install at the body part of the landslide. Similarly, two clusters of total 22 horizontal drilling drainages with $38 \mathrm{~m}$ length each were planned to install at toe part of the landslide. And in addition, the French drain (276 $\mathrm{m}$ in length), Open drain (150 m length), and Gabion toe wall for the toe of the landslide were planned and designed as well to support the additional Safety factor, (JICA, 2014). The plan of the countermeasures of the landslide is presented in the Fig. 13.

The angles between one horizontal drilling drainage to another one were kept at $10^{\circ}$ because it is practical standard angle in Japan that will be easy to operate the horizontal drilling work at site and will cover the area as much as possible in the landslide area. The Poly Vinyl Chloride (PVC) pipes having 50 $\mathrm{mm}$ diameter with required length were planned to use for the horizontal drilling drainages. The PVC pipes of required length were designed to be perforated with $\phi 6 \mathrm{~mm}$ diameter holes in $80 \mathrm{~mm}$ spacing. After completion of the required design specification, the PVC pipes were wrapped or jacketed with geo-textile to filter the fine particles, (JICA, 2014), Fig. 14.

\section{Implementation}

The installation of the five clusters of horizontal drilling drainages and construction of the French drain, Open drain and the gabion toe wall were implemented in the landslide area as per the planned and designed specifications. The works were monitored regularly to maintain their quality. The photographs of installation of horizontal drilling drainage and construction of French drain, open drain and gabion wall are presented in Fig. 15. The project work implementation period was 365 days. The project work was started from September 2013 and completed before rainy season on June 2014. The areal picture of the completed project is shown in the Fig. 16.

\section{Impact}

As the horizontal drilling drainages were started to install cluster by cluster in the landslide area, the stored ground water also started to drain out from the installed horizontal drilling 


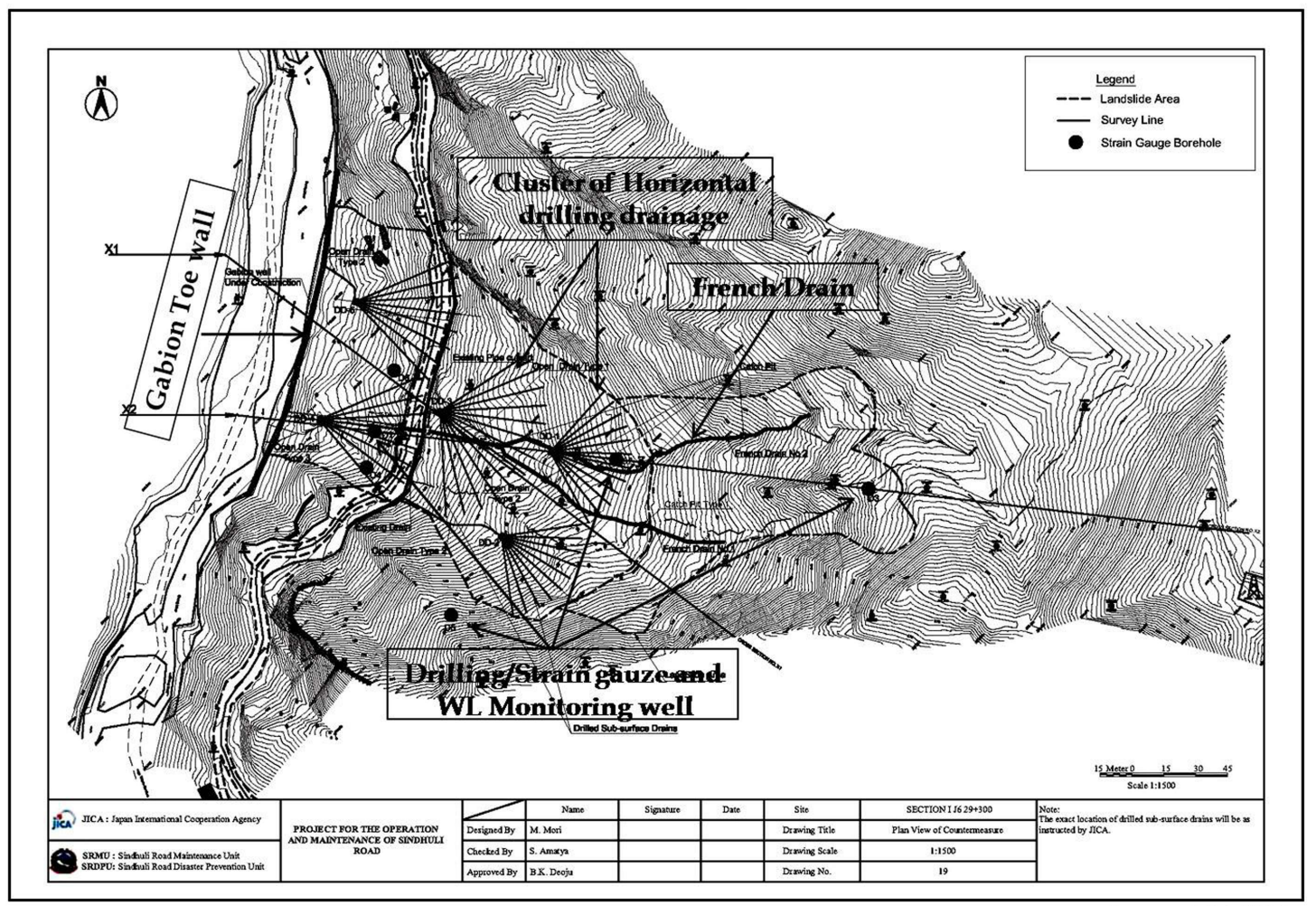

Fig. 13: Plan view of the counter measures of the landslide (source: JICA, 2014)

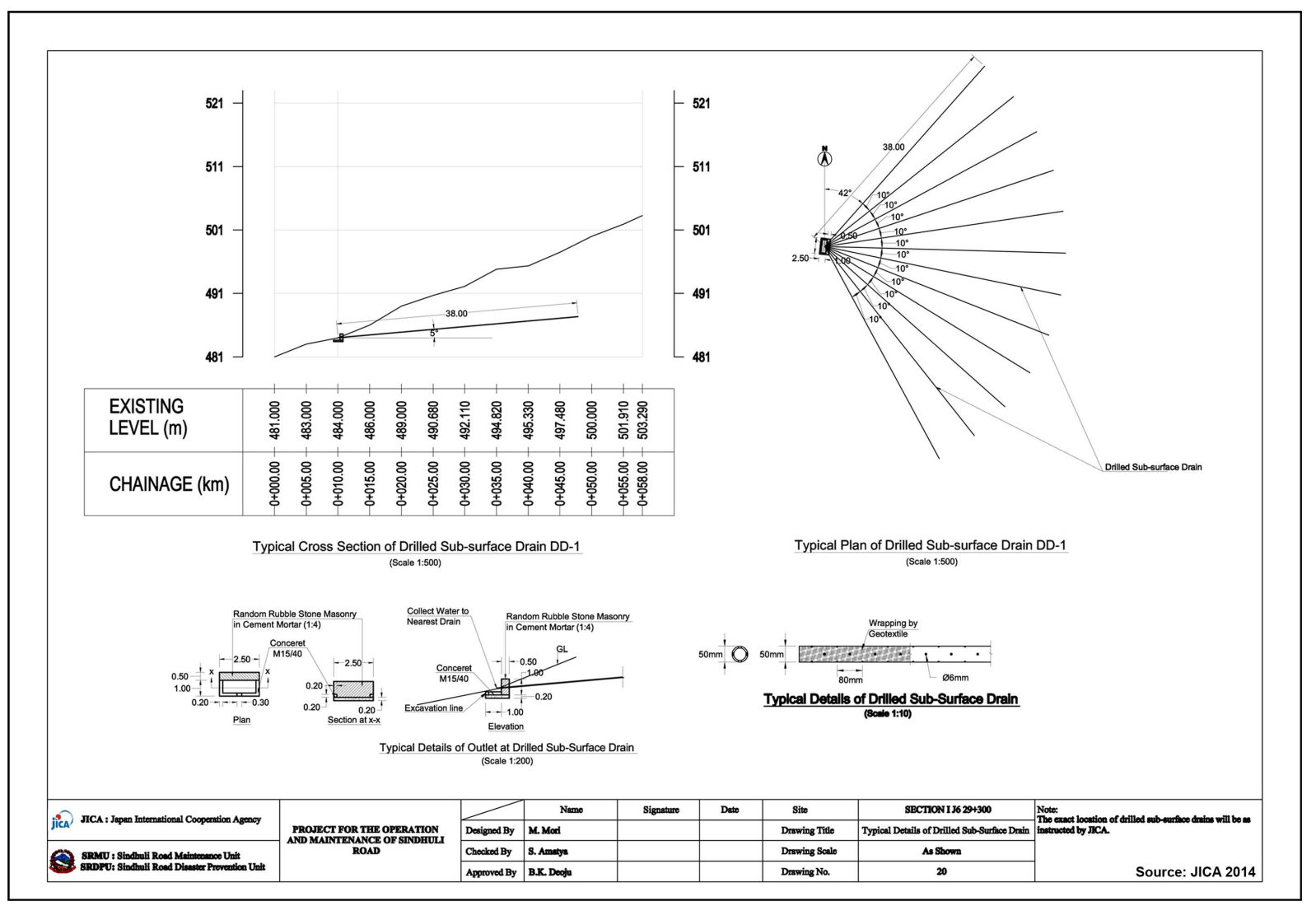

Fig. 14: Plan and design of the horizontal drilling drainage cluster (source: JICA, 2014) 


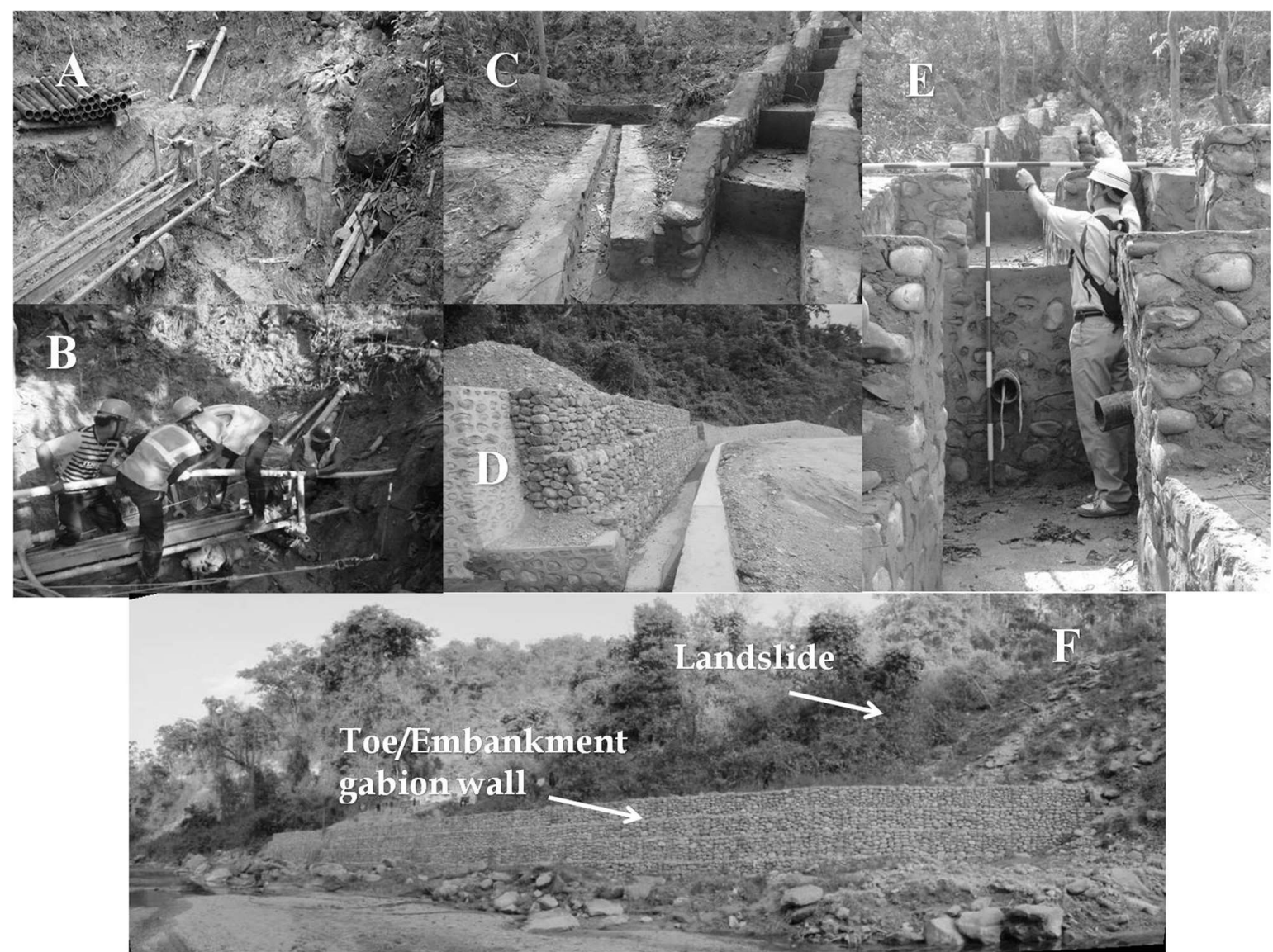

Fig. 15: Implementation of installation and construction works (A: Horizontal drilling, B: Installing PVC pipe jacketed with geo textile, C: completion of horizontal drilling drainage, D: Gabion wall, E: French drain, and F: Gabion toe/embankment wall.

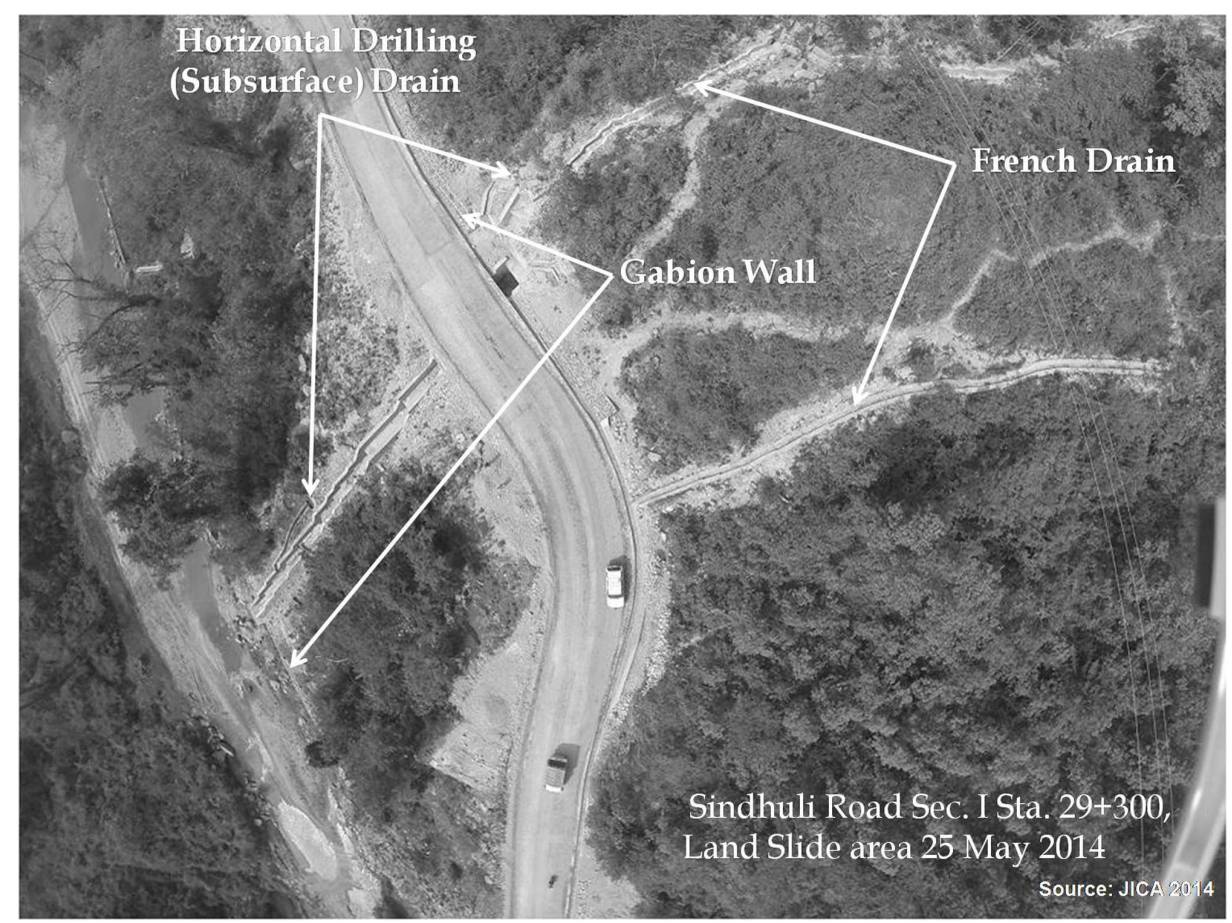

Fig. 16: Aerial photo of the completed project (source: JICA, 2014) 

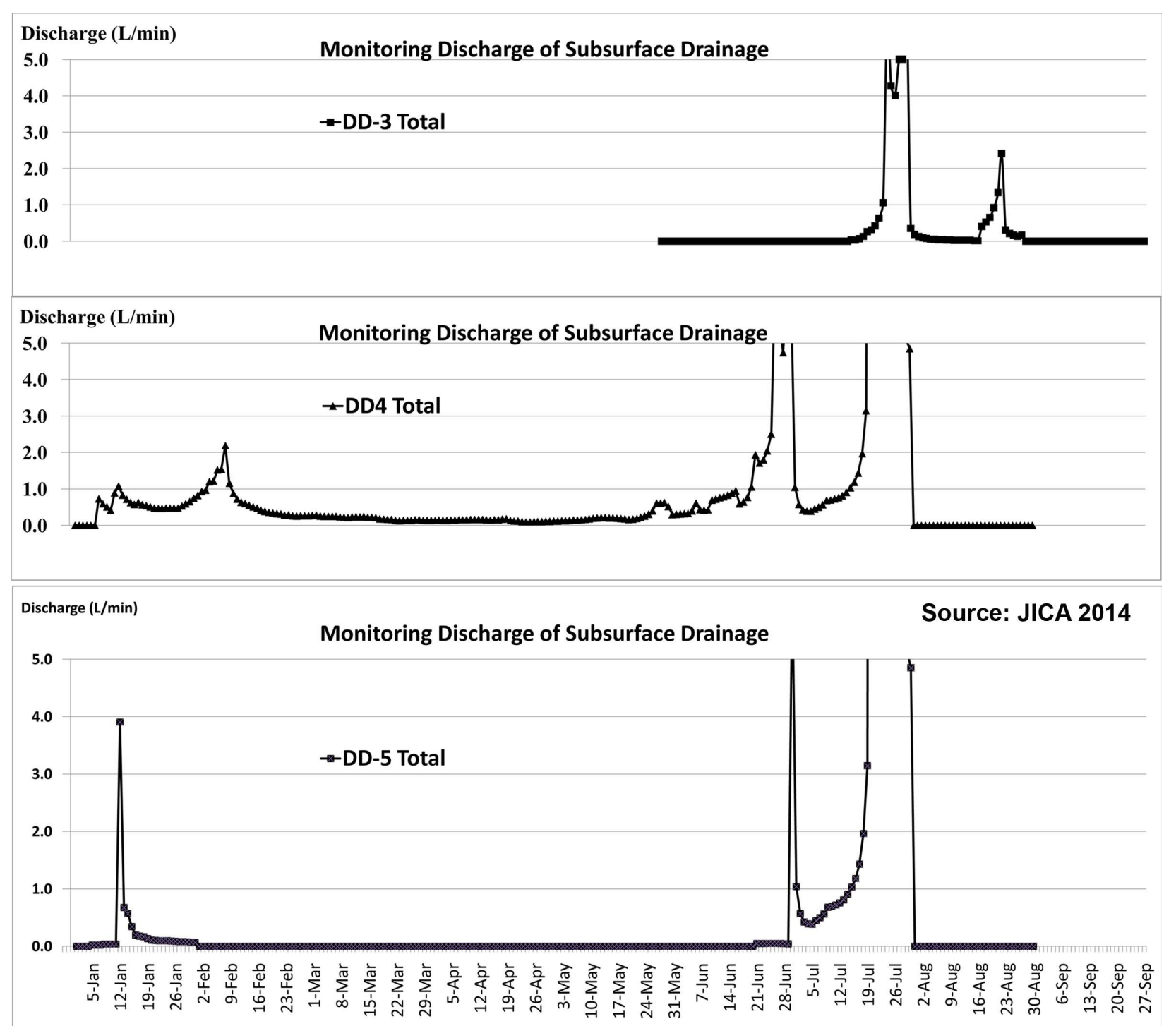

Fig. 17: Discharge graph of different clusters of horizontal drilling drainages (source: JICA, 2016)

drainages even in the dry period. The ground water level monitoring data collected from the six monitoring wells installed in the landslide area show the depletion of the water level which varies from $1.0 \mathrm{~m}$ to $4.0 \mathrm{~m}$ in different wells before rainy season (up to 2nd week of May). The discharges from the different clusters of horizontal drilling drainages were plotted in graph (Fig. 17).

The ground water level monitoring data from the six monitoring wells show the water level is slightly increased in rainy season (May onward) in compare to the dry season. But the depletion of the water level nearly became stagnant $1.0 \mathrm{~m}$ to $3.0 \mathrm{~m}$ in different monitoring wells in rainy season (May onward). The discharge of water from cluster of horizontal drilling drainage and French drain and sub-surface drain are shown in Fig. 18.
Thus, the designed Factor of safety 1.1 was satisfied with the drawdown of water level to $1.5 \mathrm{~m}$. In addition, after completion of installation of all the horizontal drilling drainages and construction of French drain, Open drain and Gabion toe wall, the average drawdown in dry and wet period was found around $3.0 \mathrm{~m}$ that gave the Fs to 1.25 which shows much more safe side from the landslide. The drawdown in different monitoring wells in the landslide area were plotted in graph and in the mean time the Fs was calculated and plotted in graph as well (Fig. 19).

In this regard, the project work was completed before rainy season on June 2014 and it was found that the landslide area became stable after completion of the implementation of the horizontal drilling drainage technology. Then the asphalt work (black top) was completed in that area as well by end of year 2015. Thus, the result obtained from the application of the 


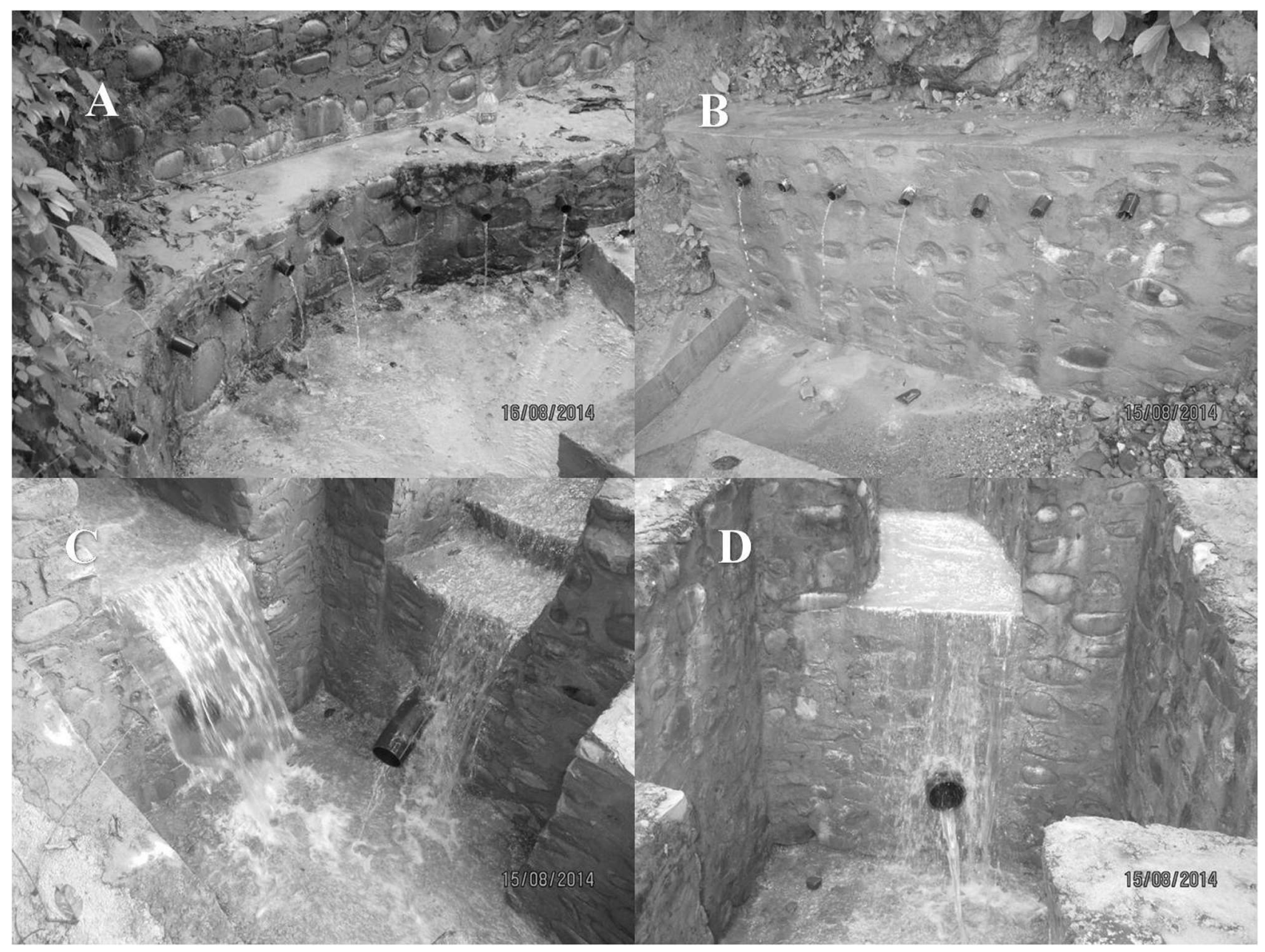

Fig. 18: Discharge of water from cluster of horizontal drilling drainage and French drain in rainy season (A and B: Discharge from horizontal drilling drainages, C: Discharge from French drain, and D: Discharge from sub-surface drainage)

horizontal drilling (subsurface) drainage method in the landslide shows an effective achievement to the Sindhuli Road stability and the road users as well.

\section{CONCLUSION}

The Sindhuli road was facing subsidence and creeping down of the land mass each year since more than ten years at Section I, 29+300, Kamalamai area, which lies on the Siwalik Range. In addition, the Gwang Khola stream accelerates the movement of the mass by toe cutting of the landslide. Thus it became a major problem to the Sindhuli Road users and Department of Road.

The survey and investigation works in that area identified the slip surface of the landslide at $10 \mathrm{~m}$ depth and the major cause of the landslide is due to the increase of pore water pressure in the landslide and toe cutting by Gwang Khola stream. Then the study team designed the Factor of Safety 1.10 of slope stability based on the environment of that landslide area.
The most effective counter measures for the pore water pressure problem in the landslide area could be the application of horizontal drilling drainage technology. The horizontal drilling drainage technology is successfully practiced in Japan which could lower the water level up to $3.0 \mathrm{~m}$ drawdown if the horizontal drilling drainage managed all over the landslide area.

The Swedish slice method was applied to analysis the slope stability. The Factor of safety was back calculated applying the Swedish slice method using different drawdown values as $1.5 \mathrm{~m}$ drawdown, $3.0 \mathrm{~m}$ drawdown and so on. The analysis shows, if the water level could be reduced by $1.5 \mathrm{~m}$ drawdown, the Factory of Safety will be 1.12 which satisfies the designed Factor of Safety and if the water level could be reduced by 3.0 $\mathrm{m}$ drawdown, the Factor of Safety will be 1.25 which exhibits the condition in much more safe side.

Thus, the five clusters of horizontal drilling drainages in total 51 horizontal drilling drainages (total length $2254 \mathrm{~m}$ ) were designed and implemented covering all the landslide area. 


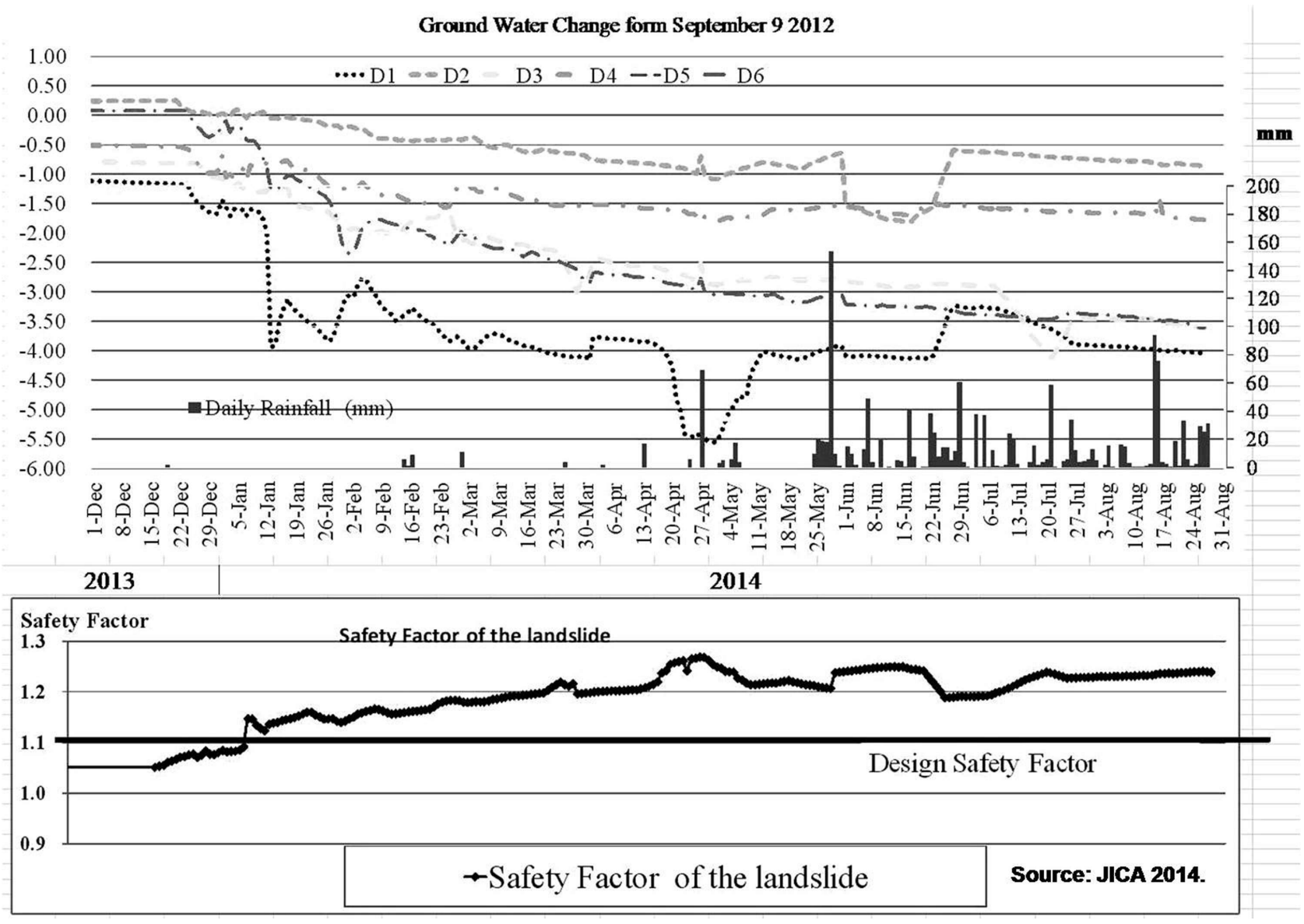

Fig. 19: Drawdown in different monitoring wells and factor of safety (source: JICA, 2014)

In addition, the French drain $(276 \mathrm{~m})$, open drain $(150 \mathrm{~m})$ and gabion toe wall were designed and implemented as well in the landslide area which could additionally support the Factor of safety of the landslide area.

In the result, the decrease of water level varied from 1-4 $\mathrm{m}$ in dry season and 1-3 $\mathrm{m}$ in wet (rainy) season in different wells which shows about $3.0 \mathrm{~m}$ drawdown in average in the landslide area.

Thus, the result satisfied the designed Factor of Safety and it was found that the landslide area became stable after completion of the implementation of the horizontal drilling drainage technology which have shown an effective achievement to the Sindhuli Road stability and the road users as well. After confirmation of the landslide stability, Department of Road completed the asphalt work (black top) as well by the end of year 2015. In this relation, the technology can be recommended to replicate in other places of the country as well in similar environment.

\section{ACKNOWLEDGEMENTS}

This study was implemented by JICA as a pilot project under "The Project for the Operation and Maintenance of the Sindhuli Road". The Department of Road (DOR), Ministry of
Physical Infrastructure and Transport, Road Board Nepal (RBN) and Department of Water Induced Disaster Management (DWIDM), Ministry of Irrigation are the major counter agencies for the project. The authors thank to JICA and JICA Experts of Consulting Engineer Nippon Koei., Co., Ltd for "The Project for the Operation and Maintenance of the Sindhuli Road" for providing the valuable information. We acknowledge JICA, Department of Road (DOR), and Department of Water Induced Disaster Management (DWIDM) for valuable support.

\section{REFERENCES}

Amatya S.C. and Joshi, J., 2015, Landslide Treatment in Nepal: by DWIDP/DSCWM, Consultative Workshop on Landslide Inventory, Risk Assessment and Mitigation in Nepal 28-29 September 2015, ICIMOD, (www.icimod.org/resources/19798).

DMG, 2004, Geological Map of Petroleum Exploration Bolck8, Janakpur, Central Nepal, First Edition, Department of Mines and Geology (DMG), Government of Nepal.

DPTC, 1999, A Technical Guideline on Landslide Mitigation Work, Water Induced Disaster Prevention Technical Centre (DPTC), Government of Nepal, 65p. 
JICA, 2014, The Project for the Operation and Maintenance of the Sindhuli Road, JICA Expert Team Sindhuli road Maintenance Unit (SRMU), Department of Roads, Ministry of Physical Infrastructure and Transport, Government of Nepal, Progress Report No.5, 118p.

JICA, 2015, The Project for the Operation and Maintenance of the Sindhuli Road, JICA Expert Team Sindhuli road Maintenance Unit (SRMU), Department of Roads, Ministry of Physical Infrastructure and Transport, Government of Nepal, Progress Report No.7, 140p.
JICA, 2016, The Project for the Operation and Maintenance of the Sindhuli Road, JICA Expert Team Sindhuli road Maintenance Unit (SRMU), Department of Roads, Ministry of Physical Infrastructure and Transport, Government of Nepal, Project Final Report, 148p.

PWRI, 2007, Guidelines for Landslide Prevention Technologies, Landslide Research Team, Erosion and Sediment Control Research Group, Public Works Research Institute (PWRI), Japan, PWRI Technical note no. 4077, 152p. 